\title{
Pulmonary Function in HIV-1 Vertically Infected Children
}

Amandine Rubio1, Fabrice Monpoux ${ }^{2 *}$, Carole Bailly ${ }^{3,4}$, Dominique Crenesse ${ }^{4}$ and Marc Albertini ${ }^{3,4}$

${ }^{1}$ Clinique Universitaire de Pédiatrie, Hôpital Couple Enfant, CHU de Grenoble, 38043 GRENOBLE cedex 09, France

${ }^{2}$ Service d'hematologie-oncologie infantile, GCS Pédiatrique CHU-Lenval, Hopital de l'Archet, 151 route de Saint Antoine de Ginestiere, 06202 NICE Cedex 3, France

${ }^{3}$ Service de Médecine Infantile, France

${ }^{4}$ Service de Physiologie et Explorations fonctionnelles, GCS Pédiatrique CHU-Lenval, Hôpital pour enfants Lenval, 57 Avenue de la Californie, 06200 NICE, France

\section{Abstract}

Background: Despite reports of an increasing incidence of asthma in HIV-infected children, exploration of pulmonary function by spirometry has never been reported in this population in the HAART era.

Objective: The aim of this study was to determine the prevalence of spirometric abnormalities in HIV-1 infected children. We conducted a cross-sectional study of pulmonary function tests (PFT) in HIV-1 vertically infected children.

Methods: Spirometric values were measured in 17 HIV-1 chronically infected children and compared to matched healthy children. In HIV-1 infected children, the correlations between PFT and the determination of the single breath carbon monoxide diffusing capacity of the lung $\left(\mathrm{TL}_{\mathrm{co}}\right)$ and immunological and virological values were assessed.

Results: Overall, 11 of the 17 PFT were normal. Four showed mild distal obstruction. Two were considered restrictive. When compared with matched healthy children, the only difference was the FEV1/FVC ratio that was significantly lower in the patients' group $(91.9 \%$ of predicted value versus $97.1 \%, p<0.0001)$. We found a positive correlation between $\mathrm{TL}_{\mathrm{co}}$ and the CD4/CD8 T-cell ratio $(p=0.012)$ and viral load $(p=0.05)$. We observed that $\mathrm{FEF}_{25-75}$ values increased with age and weight in healthy children ( $p=0.006$ and $p=0.007$ respectively), but not in infected patients.

Conclusions: Our results showed that chronic HIV-1 infection and/or continuous HAART exposure induce a specific response of the pulmonary immune system which may compromise its function with time. If confirmed, it may justify a careful follow-up of pulmonary function in vertically infected children.

Keywords: Pediatric HIV/AIDS; Pulmonary function; HAART

\section{Introduction}

Pulmonary complications have been a major cause of morbidity and mortality in children with HIV infection [1]. Before the introduction of highly active antiretroviral therapy (HAART), opportunistic pulmonary infections, mainly Pneumocystis jiroveci (carinii) pneumonia and, to a lesser extent, Streptococus pneumoniae pneumonia, were frequent, potentially lethal complications [1-4]. Introduction of HAART in the mid-eighties and improvements in prophylaxis resulted in an impressive decrease of their incidence [2-4]. Besides infections, pulmonary complications include a large number of clinical and radiological conditions in which the lung immune system plays a central role, such as lymphocytic interstitial pneumonia (LIP) or immune reconstitution inflammatory syndrome (IRIS) [1,4]. In the pre-HAART era, HIVinfected subjects had a high prevalence of respiratory complaints [5] and HIV infection was associated with accelerated development of emphysema, airway obstruction, reduced diffusing capacity for carbon monoxide and airway hyperresponsiveness [6-9].

Since the development of effective ART, obstructive lung diseases, such as asthma and chronic obstructive pulmonary disease, are becoming a growing concern in this population [9-12]. Recent studies demonstrated that 31 to $64 \%$ of HIV-infected adults have respiratory symptoms with up to $20 \%$ of airway obstruction determined by spirometry [13,14], and $20 \%$ of doctor-diagnosed asthma [15]. Likewise, a greater incidence of asthma was reported in HIV-infected versus noninfected children [16,17]. Foster et al. reported an association between HAART treatment and asthma-medication use in HIV-infected children [18]. However, we did not find any data regarding pulmonary function testing in the HAART era in HIV-infected children in the literature.

\section{Methods}

We conducted a cross-sectional study of pulmonary function tests (PFT) in HIV-1 vertically infected children followed at the Nice University Hospital. Inclusion criteria were: materno-foetal transmission, age 10 to 18 years old, no smoking, no acute or chronic lung disease and informed parental consent and child assent. Respiratory symptoms were assessed by questioning the patient and his parents regarding the prevalence of chronic cough, wheezing, shortness of breath at rest, dyspnea on exertion, use of any inhaled medication, and recurrent phlegm production.

Peripheral blood T-lymphocytes and subclass assays (CD4, CD8, CD19, CD16/56) were conducted by flow cytometry. Real-time plasma HIV RNA values were determined using the Cobas Ampliprep ${ }^{\circledR}$-Cobas TaqMan ${ }^{\circledR}$ HIV Monitor assay (Roche Diagnostics, Basel, Switzerland) according to the manufacturer's instructions. Undetectable viral load was defined as PCR-RNA below $1.60 \log _{10}$ or 40 copies $/ \mathrm{mm}^{3}$.

PFT evaluation included total lung capacity (TLC), slow vital capacity (VC), Forced expiratory flows (forced viral capacity: FVC,

*Corresponding author: Fabrice Monpoux, Hopital de l'Archet, 151 route de Sain Antoine de Ginestiere 06202 NICE Cedex 3, France, Tel: (33)-0492036122; Fax: (33)-0492036578; E-mail: monpoux.f@chu-nice.fr

Received February 14, 2012; Accepted March 22, 2012; Published March 26 2012

Citation: Rubio A, Monpoux F, Bailly C, Crenesse D, Albertini M (2012) Pulmonary Function in HIV-1 Vertically Infected Children. J AIDS Clinic Res 3:146. doi:10.4172/2155-6113.1000146

Copyright: (c) 2012 Rubio A, et al. This is an open-access article distributed unde the terms of the Creative Commons Attribution License, which permits unrestricted use, distribution, and reproduction in any medium, provided the original author and source are credited. 
forced expiratory volume in one second: $\mathrm{FEV}_{1}$ and forced expiratory flow during the middle half of FVC: $\mathrm{FEF}_{25-75}$ ) and carbon monoxide diffusing capacity $\left(\mathrm{TL}_{\mathrm{CO}}\right)$ using the single breath-hold method. Measurements were performed with a water-sealed spirometer Sensormedics 2400-Viasys (Cardinal Health Inc., Dublin, OH, USA) in accordance with international criteria [19-21]. Results were expressed as raw values and percentages of predicted values according to the anthropometric data of each patient. PFT measurements were compared to a cohort of age, height, weight and gender-matched healthy children. Comparisons of qualitative parameters were done with the Fisher's exact test. Correlations between quantitative values used regression model. Adjusted R squared values (adjusted $\mathrm{R}^{2}$ ) are furnished. Quantitative results between sub-groups of patients were compared with the MannWhitney-U-test. All statistical analyses were performed using Statview ${ }^{\circ}$ software 5.0 for Windows (SAS Institute, Cary, NC, USA). $p$ values below 0.05 are considered to indicate statistical significance.

\section{Results}

Seventeen HIV-1 chronically infected children were included: 12 girls and 5 boys, with a mean age of $14.9 \pm 2.4$ years (range: 10.8-18.3) (Table 1). Nine were HIV stage N/A, 3 were stage B and 5 suffered from AIDS definition illness. None of the children suffered from acute or chronic respiratory disease or had any respiratory symptoms determined by respiratory questionnaire and clinical examination. Mean CD4 T-cell count at inclusion was $820 \pm 301 \mathrm{cells} / \mathrm{mm}^{3}$ (range: $313-1,254$ ) or $35 \pm 10 \%$ (range: $16-50$ ). Mean viral load was $1.79 \pm 0.85$ $\log _{10}$ copies $/ \mathrm{mm}^{3}$ (range: 1.3-4.0). Twelve children had undetectable viral load. Each child had been exposed to an average of $6 \pm 3$ (range: 2-11) antiretroviral drugs since birth. At the time of enrolment, 4 patients received HAART with two nucleoside reverse transcriptase

\begin{tabular}{|l|c|c|c|}
\hline Parameters & HIV-1 infected children & Matched healthy controls & $p$ values \\
\hline Male/female ratio & $5 / 12$ & $11 / 6$ & 0.08 \\
\hline Mean age (years) & $14.9 \pm 2.4$ & $13.6 \pm 1.7$ & 0.06 \\
\hline Mean weight $(\mathrm{kg})$ & $54.8 \pm 14.4$ & $51.7 \pm 10.3$ & 0.78 \\
\hline Mean Height $(\mathrm{cm})$ & $160.4 \pm 8.9$ & $131.1 \pm 13.2$ & 0.94 \\
\hline
\end{tabular}

$p$ values: Fisher's exact test for qualitatives comparison, Mann-Whitney for quantitatives comparison.

Table 1: Patients and healthy controls' characteristics.

\begin{tabular}{|l|l|l|l|}
\hline Parameters & HIV-1 infected children & Matched healthy controls & $p$ values \\
\hline VC $(\mathrm{L})$ & $3.37 \pm 0.72(2.19-4.93)$ & $3.69 \pm 1.1(2.51-6.58)$ & 0.44 \\
\hline FEV1 $(\mathrm{L})$ & $2.90 \pm 0.64(2.05-4.59)$ & $3.25 \pm 1.0(2.21-5.53)$ & 0.34 \\
\hline FEF $_{25-75}(\mathrm{~L} / \mathrm{s})$ & $3.46 \pm 0.96(2.27-6.16)$ & $4.08 \pm 1.4(2.55-7.40)$ & 0.21 \\
\hline FEV1 / FVC (\%) & $88 \pm 6 \%(77-98)$ & $90 \pm 5 \%(82-98)$ & 0.43 \\
\hline TL $_{\text {co }(m / m n / / H g ~ m m)}$ & $24.18 \pm 9.3(15.7-57.5)$ & NA & NA \\
\hline Parameters $(p p v)$ & HIV-1 infected children & Matched healthy controls & \\
\hline VC & $101.4 \pm 14.7 \%$ & $103.5 \pm 15.5 \%$ & 0.98 \\
\hline FEV-1 & $92.6 \pm 12.5 \%$ & $100.2 \pm 13.9 \%$ & 0.052 \\
\hline FEF & $98.1 \pm 21.2 \%$ & $112.1 \pm 24.6 \%$ & 0.14 \\
\hline FEV1 / FVC & $91.9 \pm 7.7 \%$ & $97.1 \pm 6 \%$ & $<0.0001$ \\
\hline TL $_{\text {co }}$ & $102.9 \pm 23.8 \%$ & NA & \\
\hline
\end{tabular}

mean \pm standard deviation and range for spirometric values. HIV-1 vertically infected children ( $n: 17)$ and healthy matched control (n: 17). Units: (L) liter, (L/s) liter per second, $(\mathrm{ml} / \mathrm{min} / \mathrm{Hg} \mathrm{mm})$ milliliter per minute per $\mathrm{Hg}$ millimeter. NA: non available, ppv: percentage of predicted value. Mean \pm standard deviation for spirometric values expressed as percentages of predicted values according to the anthropometric data of each patient.

$p$ values: Mann-Whitney comparison inhibitors (NRTI) and 1 protease inhibitor (PI), 11 received 2 NRTIs + 1 non nucleoside reverse transcriptase inhibitor (NNRTI), 1 was on PI monotherapy, and 1 was receiving 1 drug of each class (NRTI + NNRTI $+\mathrm{PI})$.

All of the children underwent successful PFT. Spirometric data were analyzed by 2 separate practitioners (CPB, MA). Overall, 11 of the 17 tests were normal. Four showed mild distal obstruction $\left(\mathrm{FEF}_{25}\right.$ ${ }_{75}<70 \%$ of the predicted value), with salbutamol reversibility. Two spirometric evaluations were considered restrictive (TLC $<80 \%$ of the predicted value). All $\mathrm{TL}_{\mathrm{CO}}$ and $\mathrm{FEV1/FVC} \mathrm{ratios} \mathrm{were} \mathrm{in} \mathrm{the} \mathrm{normal}$ ranges $\left(\mathrm{TL}_{\mathrm{CO}}>80 \%\right.$ of the predicted value and $\mathrm{FEV} 1 / \mathrm{FVC}>80 \%$ ) (Table 2). We found a positive correlation between $\mathrm{TL}_{\mathrm{CO}}$ and haemoglobin level $(\mathrm{p}=0.002), \mathrm{CD} 8$ percentage $(\mathrm{p}=0.05), \mathrm{CD} 4 / \mathrm{CD} 8 \mathrm{~T}$-cell ratio $(\mathrm{p}=0.012$ $-\mathrm{R}^{2}: 0.35$ - Figure 1), viral load $\left(\mathrm{p}=0.05, \mathrm{R}^{2}: 0.24\right)$ and $\mathrm{FEF}_{25-75}(\mathrm{p}=$ $\left.0.015, \mathrm{R}^{2}: 0.33\right) . \mathrm{FEF}_{25-75}$ values were correlated with leucocytes count $(\mathrm{p}=0.05)$, haemoglobin level $(\mathrm{p}=0.03)$, percentage of CD4 $(\mathrm{p}=0.02)$ and CD8 ( $\mathrm{p}=0.04)$ T-cells and CD4/CD8 ratio (Figure 1). We did not find any correlation between $\mathrm{TL}_{\mathrm{CO}}$ or $\mathrm{FEF}_{25-75}$ and $\mathrm{CD} 19^{+} \mathrm{B}$-lymphocytes, CD16/56 ${ }^{+}$NK cells, absolute CD4 or CD8 T-cells counts or duration of drug exposure.

When compared with matched healthy children, the only difference was the FEV1/FVC ratio that was significantly lower in the patients' group $(91.9 \%$ of predicted value versus $97.1 \%, \mathrm{p}<0.0001$ ) (Tables 1 and 2). Furthermore, although $\mathrm{FEF}_{25-75}$ values were similar in the two groups, we observed that this parameter increased with age and weight in healthy children ( $\mathrm{p}=0.006$ and $\mathrm{p}=0.007$ respectively), as was reported by Neukirch et al. [22], but not in infected patients (Figure 2).

\section{Discussion}

Our data shows that in vertically HIV-1 infected non-smoking adolescents, PFT values are in normal ranges, with a high prevalence of sub-clinical mild and reversible basal obstructive ventilatory impairment, as was observed in adult patients $[9,10,14]$. Similarly, in 1997 de Martino et al. published that children with perinatally acquired HIV-1 infection had higher airway resistance than matched controls, and that resistance decreased with age in the latter but not in infected patients [23]. We also observed that $\mathrm{TL}_{\mathrm{CO}}$ analysis, which is a measure of gas exchange potential [24], demonstrated a strong correlation with the CD4/CD8 T-cell ratio and viral replication. In the mid-nineties, decreases in the $\mathrm{TL}_{\mathrm{CO}}$ were described in patients with infectious lung disease, mainly Pneumocystis pneumonia [9-12]. In 1995, Rosen et al. published that advanced HIV infection, characterized by CD4 count $<200 / \mathrm{mm}^{3}$ or HIV-associated symptoms, were all associated with reductions in $\mathrm{TL}_{\mathrm{CO}}$ measurements [9]. Conversely, Nieman et al. showed that patients with reduced $\mathrm{TL}_{\mathrm{CO}}$ progressed more rapidly to AIDS [11]. $\mathrm{TL}_{\mathrm{CO}}$ reduction may result from two main mechanisms: diffuse alveolar destruction (as observed in Pneumocystis pneumonia, pulmonary hypertension or fibrosis) or a decrease in alveolar expansion (as observed in neuromuscular disease) [24]. Patients with HIV infection receiving HAART may potentially suffer from each of these two mechanisms.

Recent data supported the fact that in adult patients, the use of HAART is independently associated with a decrease in FEV1/FVC after controlling for other independent risk factors such as age, cigarette smoking, intra venous drug use or previous pneumonia [14,15]. In our population, we also found a significantly lower FEV1/FVC ratio in our patients than in controls. Foster et al. suggested that the increased incidence of asthma in HAART-treated HIV-infected children may be driven by immunoreconstitution of CD4 T-cells [18]. They indeed 

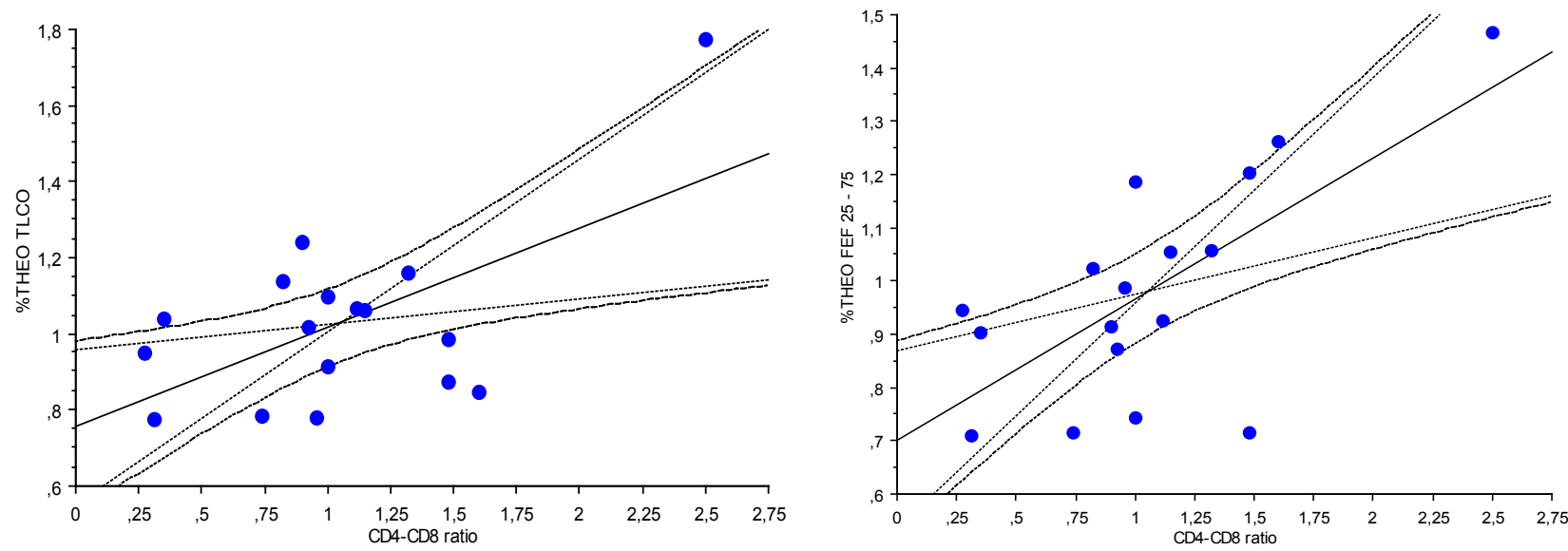

Figure 1: Correlation between $\mathrm{TL}_{\mathrm{CO}}\left(\% \mathrm{THEO} \mathrm{TL}_{\mathrm{CO}} /\right.$ left / $\left.\mathrm{p}=0.012\right), \mathrm{FEF}_{25-75}\left(\% \mathrm{THEO} \mathrm{FEF}_{25-75} /\right.$ right / $\left.\mathrm{p}=0.03\right)$ and $\mathrm{CD}_{4} / \mathrm{CD} 8^{+} \mathrm{T}$ cell ratio, mean and slope. Full lines: slope; dotted lines: $95 \%$ confidence intervals
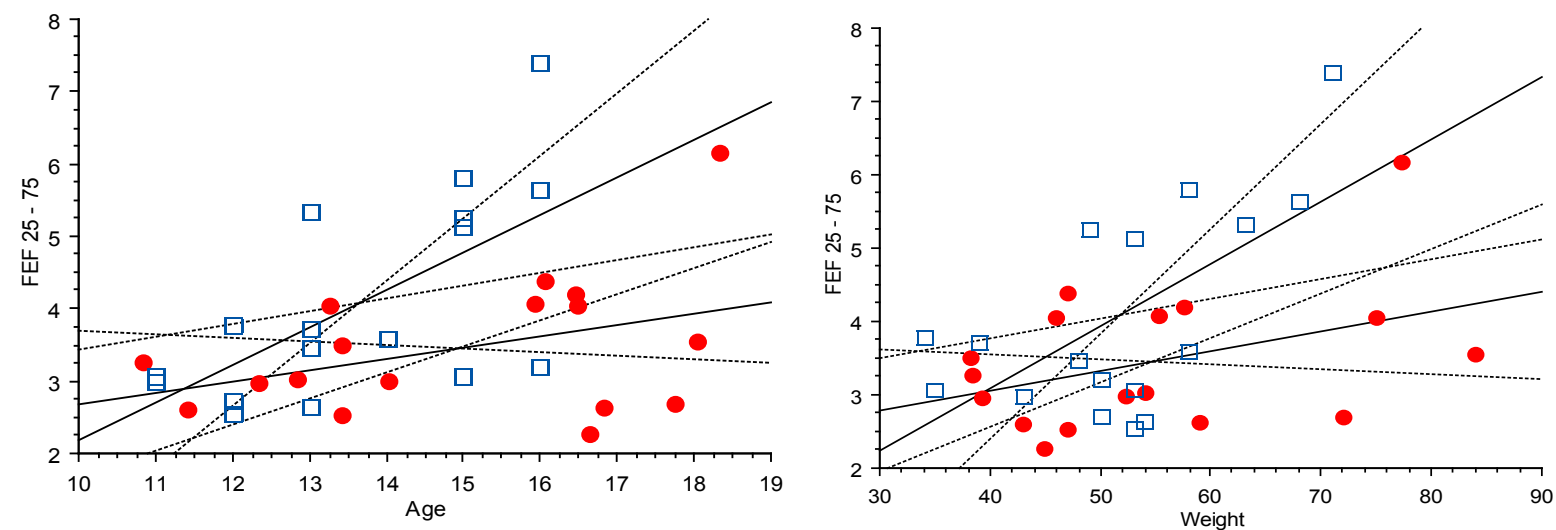

Figure 2: Correlation between $\mathrm{FEF}_{25-75}$ and age (years / left) and weight (kg / right) in HIV-1 vertically infected children (dot) and matched healthy controls (square). $\mathrm{FEF}_{25-75}$ is correlated with age and weight in healthy children but not in $\mathrm{HIV}-1$ chronically infected children. $\mathrm{FEF}_{25-75}=1.13+0.156^{*}$ age; $\mathrm{R}^{2}=0.149-\mathrm{NS}(\mathrm{HIV}-1$ infected children), $\mathrm{FEF}_{25-75}=-3.005+0.519^{*}$ age; $\mathrm{R}^{2}=0.408-\mathrm{p}=0.006$ (matched healthy children). $F E F_{25-75}=1.985+0.27^{*}$ weight; $R^{2}=0.163-\mathrm{NS}$ (HIV-1 infected children), $\mathrm{FEF}_{25-75}=-0.317+0.085^{*}$ weight; $\mathrm{R}^{2}=0.392-\mathrm{p}=0.007$ (matched healthy children). NS: non significant.

Full lines: slope; dotted lines: $95 \%$ confidence intervals.

showed that HIV+ HAART-treated children had the same cumulative incidence of asthma (around $30 \%$ by the age of 13) as non-infected children, whereas HIV-positive untreated children (who had lower CD4 and higher CD8 T cell percentages) had a thrice-lower incidence of asthma. This is indeed supported by the notion that CD4 T-cells are essential for the development of asthma in animal models $[25,26]$. Likewise, Gutin and Secord reported that the onset of asthma in HIVinfected children most frequently occurred within 3 years of beginning HAART [27]. Despite the fact that our patients were HAART-treated, none had developed asthma, and we did not find a significant relationship between FEV1 or FEV1/FVC and CD4+ or CD8+ T-cell counts or percentages in our patients. This could be explained by the relatively small sample size of our population.

We found however evidence of small-diameter bronchi obstruction (reduction in $\mathrm{FEF}_{25-75}$ in 4/17 of our patients), and a positive correlation between plasmatic $\mathrm{CD} 4 / \mathrm{CD} 8$ ratio and $\mathrm{FEF}_{25-75}$. It is possible that in pediatric patients, alterations of $\mathrm{FEF}_{25-75}$ may reflect or precede those observed in adult larger bronchi. Unfortunately none of our patients underwent broncho-alveolar liquid fluid (BALF) analysis or high resolution CT-scan. But even if the blood immuno-virological status does not reflect the exact events arising at the alveolar level, it is possible that our results reflect a particular response of the lungs to infection. In 1997 Lipman et al. compared BALF analysis (cells and cytokine levels) from HIV-1 infected patients with pneumonia and HIV-1 positive individuals with no respiratory disease to healthy controls and showed that alteration of the potential relevance to the pulmonary immune response are occurring in alveolar macrophages prior to the onset of respiratory disease [28]. Actual evidence for pulmonary tissue-level effects of HIV is conflicting. Alveolar macrophages and dendritic cells within the lung are targets for HIV infection and become increasingly infected as HIV infection progresses [3]. We recently showed that children's response to HAART is nowadays similar to that of adults with approximately $80 \%$ achieving an undetectable viral load and a good immunological response [29]. It is likely that with HAART, the plasmatic viral load decrease is associated with a reduction in the overall HIV lung concentration. 
Altogether, the mechanistic link between HAART and airway obstruction is not precisely known. Potential explanations include: a) direct effects of HAART in the lung; b) chronic stimulation of inflammation induced by restoration of the immune system, with the release by CD8+ T-cells of inflammatory cytokines known to be implicated in airway inflammation [15]; c) the development of a hyperallergic state [16], as was shown by a higher sputum eosinophil count [15]; d) and/or the development of autoimmunity.

Although evidence of airway obstruction was small in our vertically HIV-infected HAART-treated pediatric population, these subjects face a lifetime of antiretroviral treatment and may be at risk of developing clinically significant disease as they age. Smoking avoidance, routine influenza and pneumococcal vaccinations and careful pulmonary follow-up must therefore be combined to decrease the risk of respiratory symptoms and airway obstruction in these patients.

\section{Acknowledgements}

The authors thank all of the participating children and their families. The assistants who performed the spirometry test: Mme Valerie Foussard, Andree Leger, Nadine Treillet, and the nurses: Marie Soumah, Christelle Falzon.

\section{References}

1. Mouzinho A (2004) Pulmonary complications of HIV. Pediatr Pulmonol 26: $57-$ 58.

2. Nesheim SR, Kapogiannis BG, Soe MM, Sullivan KM, Abrams E, et al. (2007) Trends in opportunistic infection in the pre and post highly active antiretroviral therapy eras among HIV-infected children in the perinatal AIDS collaborative transmission study, 1986-2004. Pediatrics 120: 100-109.

3. Hull MW, Phillips P, Montaner JS (2008) Changing global epidemiology of pulmonary manifestations of HIVIAIDS. Chest 134: 1287-1298.

4. Zar HJ (2008) Chronic lung disease in human immunodeficiency virus (HIV) infected children. Pediatr pulmonol 43: 1-10.

5. Diaz PT, Wewers MD, Pacht E, Drake J, Nagaraja HN, et al. (2003) Respiratory symptoms among HIV-seropositive individuals. Chest 123: 1977-1982.

6. O'Donnell CR, Bader MB, Zibrak JD, Jensen WA, Rose RM (1988) Abnormal airway function in individuals with the acquired immunodeficiency syndrome. Chest 94: 945-948.

7. Poirier CD, Inhaber N, Lalonde RG, Ernst P (2001) Prevalence of bronchial hyperresponsiveness among HIV-infected men. Am J Respir Crit Care Med 164: 542-545.

8. Wallace JM, Stone GS, Browdy BL, Tashkin DP, Hopewell PC, et al. (1997) Nonspecific airway hyperresponsiveness in HIV disease. Pulmonary Complications of HIV Infection Study Group. Chest 111: 121-127.

9. Rosen MJ, Lou Y, Kvale PA, Rao AV, Jordan MC, et al. (1995) Pulmonary function test in HIV-infected patients without AIDS. Pulmonary complications infection of HIV infection study group. Am J Respir Crit Care Med 152: 738-745.

10. Mitchell DM, Clarke JR (1996) The lung in HIV infection: can pulmonary function testing help? Monaldi Arch Chest Dis 51: 214-222.

11. Nieman RB, Fleming J, Coker RJ, Harris JR, Mitchell DM (1993) Reduced carbon monoxide transfer factor (TLCO) in human immunodeficiency virus type I (HIV-I) infection as a predictor for faster progression to AIDS. Thorax 48: 481485 .

12. Pothoff G, Wassermann K, Julius B, Hilger HH (1992) Pulmonary function tests after pneumocystis carinii pneumonia in HIV infected patients. Pneumologie 46: 221-225.

13. Gingo MR, George MP, Kessinger CJ, Lucht L, Rissler B, et al. (2010) Pulmonary function abnormalities in HIV-infected patients during the current antiretroviral therapy era. Am J Respir Crit Care Med 182: 790-796.

14. George MP, Kannass M, Huang L, Sciurba FC, Morris A (2009) Respiratory symptoms and airway obstruction in HIV-infected subjects in the HAART era. PLoS One 4: e6328.
15. Gingo MR, Wenzel SE, Steele C, Kessinger CJ, Lucht L, et al. (2012) Asthma diagnosis and airway bronchodilator response in HIV-infected patients. J Allergy Clin Immunol 129: 708-714.

16. Siberry GK, Leister E, Jacobson DL, Foster SB, Seage GR 3rd, et al. (2012) Increased risk of asthma and atopic dermatitis in perinatally HIV-infected children and adolescents. Clin Immunol 142: 201-208.

17. Gutin F, Butt A, Alame W, Thomas R, Secord E (2009) Asthma in immunecompetent children with human immunodeficiency virus. Ann Allergy Asthma Immunol 102: 438.

18. Foster SB, McIntosh K, Thompson B, Lu M, Yin W, et al. (2008) Increased incidence of asthma in HIV-infected children treated with highly active antiretroviral therapy in the National Institutes of Health Women and Infants Transmission Study. J Allergy Clin Immunol 122: 159-165.

19. Miller MR, Hankinson J, Brusasco V, Burgos F, Casaburi R, et al. (2005) Standardisation of spirometry. Eur Respir J 26: 319-338.

20. Wanger J, Clausen JL, Coates A, Pedersen OF, Brusasco V, et al. (2005) Standardisation of the measurement of lung volumes. Eur Respir J 26: 511 522.

21. Macintyre N, Crapo RO, Viegi G, Johnson DC, van der Grinten CP, et al. (2005) Standardisation of the single-breath determination of carbon monoxide uptake in the lung. Eur Respir J 26: 720-735.

22. Neukirch F, Chansin R, Liard R, Levallois M, Leproux $P$ (1988) Spirometry and maximal expiratory flow-volume curve reference standards for Polynesian, European, and Chinese teenager. Chest 94: 792-798.

23. de Martino M, Veneruso G, Gabiano C, Frongia G, Tulisso S, et al. (1997) Airway resistance and spirometry in children with perinatally acquired human immunodeficiency virus-type 1 infection. Pediatr Pulmonol 24: 406-414.

24. Hughes JM (2007) Assessing gas exchange. Chron Respir Dis 4: 205-214.

25. Gavett SH, Chen X, Finkelman F, Wills-Karp M (1994) Depletion of murine CD4+ $\mathrm{T}$ lymphocytes prevents antigen-induced airway hyperreactivity and pulmonary eosinophilia. Am J Respir Cell Mol Biol 10: 587-593.

26. Chapoval SP, Marietta EV, Smart MK, David CS (2001) Requirements for allergen-induced airway inflammation and hyperreactivity in CD4-deficient and CD4-sufficient HLA-DQ transgenic mice. J Allergy Clin Immunol 108: 764-771.

27. Gutin F, Secord E (2004) HIV-related risk factors for asthma in children. J Allergy Clin Immunol 113: S127.

28. Lipman MC, Johnson MA, Poulter LW (1997) Functionally relevant change occur in HIV-infected individual's alveolar macrophage prior the onset of respiratory disease. AIDS 11: 765-772.

29. Monpoux F, Pugliese P, Bertier F, Cottalorda J, Pradier C (2009) Bridging the gap between adult and paediatric outcomes in HIV-1 vertically infected children: a single-centre comparison with adult data. Acta Paediatr 98: 1787-1792. 